\title{
Removal of bentazone from micro-polluted water using MIEX resin: Kinetics, equilibrium, and mechanism
}

\author{
Zequn Liu ${ }^{1}$, Xiaomin Yan ${ }^{1}$, Mary Drikas ${ }^{2}$, Danong Zhou ${ }^{3}$, \\ Dongsheng Wang ${ }^{1, *}$, Min Yang ${ }^{1}$, Jiuhui $\mathrm{Qu}^{1}$ \\ 1. State Key Laboratory of Environmental Aquatic Chemistry, Research Center for Eco-Environmental Sciences, \\ Chinese Academy of Sciences, Beijing 100085.E-mail: wgds@rcees.ac.cn \\ 2. Australian Water Quality Center, South Australia Water Corporation, Victoria Square 250, Adelaide, SA 5000, Australia \\ 3. No.9 Water Plant, Beijing Waterworks Group, Beijing 100192, China
}

Received 22 March 2010; revised 05 June 2010; accepted 22 June 2010

\begin{abstract}
The contamination of surface and ground water by bentazone has attracted increasing global concern in recent years. We conducted a detailed investigation using MIEX resin to eliminate bentazone from waters. Batch experiments were carried out to evaluate the effect of process parameters, such as retention time, resin amount, and initial pesticide concentration, on removal efficiency of bentazone. Results showed the sorption process was fast and bentazone could be efficiently removed in 30 minutes. The kinetic process of bentazone sorption on MIEX resin was well described by pseudo second-order model and intraparticle diffusion was the rate controlling step. The MIEX resin possessed the highest sorption capacity of $0.2656 \mathrm{mmol} / \mathrm{mL}$ for bentazone according to Langmuir fitting. Bentazone is a hydrophobic ionizable organic compound, and both ionic charge and hydrophobic aromatic structure governed the sorption characteristics on MIEX resin. The different removal efficiencies of ionic and non-ionic pesticides, combined with the charge balance equations of bentazone, $\mathrm{SO}_{4}{ }^{2-}, \mathrm{NO}_{3}{ }^{-}$and $\mathrm{Cl}^{-}$, indicated that removal of bentazone using MIEX resin occurred primarily via ion exchange.
\end{abstract}

Key words: bentazone; MIEX resin; ion exchange; micro-polluted water

DOI: $10.1016 / \mathrm{S} 1001-0742(10) 60441-X$

Citation: Liu Z Q, Yan X M, Drikas M, Zhou D N, Wang D S, Yang M et al., 2011. Removal of bentazone from micro-polluted water using MIEX resin: Kinetics, equilibrium, and mechanism. Journal of Environmental Sciences, 23(3): 381-387

\section{Introduction}

Pesticide contamination of surface and ground water has attracted increasing global concern (Cohen et al., 1986; Gerstl, 1991). Bentazone is one of the most widely used herbicides around the world and has a negative effect on human eyes and skin. It is a triazin herbicide and blocks photosynthesis in dicotyledonous plants by inhibition of the electron transport system (Huber and Otto, 1994). Herbicides are usually more soluble in water and less adsorbed to soil than other pesticides and, hence, are more easily leached into ground water (Carrizosa et al., 2000). Recently, bentazone has been detected in both surface and ground water (Streat and Horner, 2000).

Adsorption on activated carbon is widely used to treat pesticide pollution in water, such as the sorption of atrazine, metribuzin, bromacil, 2,4-D and bentazone on high area carbon cloth (Pelekani and Snoeyink, 2000; Ayranci and Hoda, 2004; Ania and Béguin, 2007). Although results have shown good pesticide removal

\footnotetext{
* Corresponding author. E-mail: wgds@ rcees.ac.cn
}

efficiency, the disadvantage associated with activated carbon is the high regeneration cost and the generation of carbon fines. In addition, nanofiltration, reverse osmosis, and advanced oxidation processes are used to eliminate pesticide contamination in aquatic solutions (Caus et al., 2009; Abdessalem et al., 2009). The wide use of these technologies is, however, hampered by the formation of undesirable oxidation by-products and membrane fouling (Kobayashi et al., 1990; Taylor and Hong, 2000).

Ion exchange resins were first used for water softening and mainly applied to inorganic ion removal. These resins became of concern after studies demonstrated the strong potential of anion exchange resins for removal of natural organic matter (NOM). Anion exchange resins are more effective for NOM removal than non-ionic resins, activated carbon, and cationic polymers (Anderson and Maier, 1979; Boening et al., 1980; Bolto et al., 2002). Ion exchange resins can also deal with micro-pollutants, such as pentachlorophenol, 2,4,6-trichlorophenol, 2,6-dichlorophenol and phenol (Li and Sengupta, 1998; Carmona et al., 2006). Until now, however, few studies have been conducted on bentazone removal using ion exchange resins and the 
mechanism of organic substance uptake by anion exchange resins remains unclear.

Magnetic ion exchange resin (MIEX) was developed by Orica Watercare and South Australian Water Corporation. In contrast to traditional anion exchange resins, MIEX resin has two specific characteristics. First, the MIEX resin has magnetized iron oxide incorporated into the polymer matrix. The magnetic component aids agglomeration and allows high settlement rate with a relatively small particle size. Second, the resin is applied to raw water in a slurry form and mixed well with adsorbate by machine stirring, thus decreasing the resistance to liquid phase mass transfer (Singer and Bilyk, 2002). MIEX resin is widely used in removing NOM, thereby lowering the need for coagulation and reducing disinfection by-products (DBPs) formation of the water (Singer and Bilyk, 2002; Fearing et al., 2004; Boyer and Singer, 2005).

Accordingly, we investigated the effectiveness of MIEX on the removal of ionic herbicide bentazone. Batch experiments were carried out for kinetic and sorption equilibrium studies on the removal of bentazone from aquatic solutions. Charge balance equations for $\mathrm{Cl}^{-}$and bentazone and other inorganic ions were calculated to quantify the contributions of ion exchange and adsorption to bentazone removal. The removal results of another ionic herbicide glyphosate and nonionic pesticide parathion-methyl by MIEX resin were compared with bentazone to clarify the mechanism of bentazone uptake by MIEX resin.

\section{Materials and methods}

\subsection{Materials}

MIEX resin was received in slurry form (the volume ratio of resin and water was about 1:1 for $12 \mathrm{hr}$ settlement) and the suspended liquid was stirred to maintain a well mixed phase before each MIEX experiment. The pesticide bentazone, glyphosate, and parathion-methy with purity 99.3\% were all obtained from the J. K. Chemical Corporation (China). The physico-chemical properties of the three pesticides are shown in Table 1. Methanol, used as the mobile phase, was of HPLC grade. All other solutions were prepared from analytical grade chemicals and Milli-Q water. Glyphosate solution was prepared in polypropylene bottles to avoid possible adsorption of glyphosate on glass surface. All the other reagents were stored in glass containers at $4^{\circ} \mathrm{C}$.

\subsection{Experimental methods}

All batch ion-exchange studies were conducted by shaking $(200 \mathrm{r} / \mathrm{min})$ for a period of time at a controlled temperature of $(25 \pm 1)^{\circ} \mathrm{C}$ in $250 \mathrm{~mL}$ sealed pyramid glass bottles with MIEX resin and $100 \mathrm{~mL}$ pesticide and inorganic ions solution. After agitation, the solid was removed by filtration through a $0.45 \mu \mathrm{m}$ cellulose filter membrane. The final pesticide and inorganic ions concentration in the filtrates as well as in the initial solutions were determined. To correct for any adsorption of pesticide on the container surface, control experiments were carried out in the absence of resins. All experiments were performed in duplicates and the results were taken as the average value.

For resin dose effect, the initial concentration of bentazone solution was $0.08 \mathrm{mmol} / \mathrm{L}$. MIEX resin doses in the range of $1-10 \mathrm{~mL} / \mathrm{L}$ were tested. The solutions were shaken for $2 \mathrm{hr}$.

Three different initial concentrations of bentazone $(0.04$, 0.08 , and $0.12 \mathrm{mmol} / \mathrm{L}$ ) were used to study the sorption kinetic process on the ion-exchange resin. MIEX resin dose was fixed at $4.2 \mathrm{~mL} / \mathrm{L}$. The concentration of bentazone from the aqueous solution was determined at certain time intervals.

Sorption isotherms were determined with different initial concentrations varying from 0.01 to $1.8 \mathrm{mmol} / \mathrm{L}$ of bentazone and 0.01 to $0.6 \mathrm{mmol} / \mathrm{L}$ of glyphosate, while resin amount remained constant at $4.2 \mathrm{~mL} / \mathrm{L}$. The agitation time was $2 \mathrm{hr}$, which was sufficient to reach equilibrium.

To evaluate the ion exchange mechanism of MIEX resin for bentazone, two experiment systems with an initial concentration molecular ratio $1 / 1$ for bentazone $/ \mathrm{SO}_{4}{ }^{2-}$ and bentazone $/ \mathrm{NO}_{3}{ }^{-}$were carried out, respectively. The experimental conditions were the same for bentazone sorption isotherm determination.

Table 1 Structural formula and properties of the three pesticides

\begin{tabular}{|c|c|c|c|c|c|}
\hline Herbicide & Chemical formula & Structural formula & Molecular weight & Solubility in $\mathrm{H}_{2} \mathrm{O}(\mathrm{mg} / \mathrm{L})$ & $\mathrm{p} K_{\mathrm{a}}$ \\
\hline Bentazone & $\mathrm{C}_{10} \mathrm{H}_{12} \mathrm{~N}_{2} \mathrm{O}_{3} \mathrm{~S}$ & & 240.28 & 500 & 3.3 \\
\hline Glyphosate & $\mathrm{C}_{3} \mathrm{H}_{8} \mathrm{NO}_{5} \mathrm{P}$ & $\mathrm{O}$ & 169.08 & $1.2 \times 10^{4}$ & $0.8,2.22,5.44,10.13$ \\
\hline Parathion-methy & $\mathrm{C}_{8} \mathrm{H}_{10} \mathrm{NO}_{5} \mathrm{PS}$ & & 263.13 & 55 & - \\
\hline
\end{tabular}


Bentazone was determined by HPLC directly. Glyphosate sample was first derivatized with p-toluenesulphonyl chloride solution and borate buffer for $4 \mathrm{hr}$ at room temperature before being injected into HPLC. The HPLC system was a Waters 1515 system with a UV-detector. Isocratic separation was performed on a Waters sunfire, $250 \mathrm{~mm} \times 4.6 \mathrm{~mm}, \mathrm{C} 18$ column at $35^{\circ} \mathrm{C}$. Mixtures of methanol/0.02 mol/L $\mathrm{KH}_{2} \mathrm{PO}_{4}(66 / 34, V / V$, $\mathrm{pH}=2.8$, adjusted by $\mathrm{H}_{3} \mathrm{PO}_{4}$ solution) for bentazone or methanol $/ 0.05 \mathrm{~mol} / \mathrm{L} \mathrm{NaH}_{2} \mathrm{PO}_{4}(20 / 80, V / V, \mathrm{pH}=$ 5.5 , adjusted by $\mathrm{NaOH}$ solution) for glyphosate were used as the mobile phase at $1 \mathrm{~mL} / \mathrm{min}$, respectively. The detection wavelengths were 218 for bentazone and 240 $\mathrm{nm}$ for glyphosate. The sample volumes injected were both $20 \mu \mathrm{L}$. Inorganic ions were determined by ICS-1000 (American Dionex).

\section{Results and discussion}

\subsection{Effect of does of MIEX resin on bentazone removal}

The effect of dose of MIEX resin for pesticide removal is important for determining adsorbent capacity and percentage removals of pesticide at an optimum resin dose. Figure 1 shows the removal of bentazone as a function of MIEX resin amount. Results showed that sorption efficiency increased when resin amount increased. The percentage of bentazone removal increased from $90 \%$ to $98.8 \%$ with an increase in resin from 1 to $10 \mathrm{~mL} / \mathrm{L}$. But the sorption density decreased with increasing resin amount. At a fixed initial solute concentration, greater sorption sites are provided by a higher resin amount, resulting in an increase in solute removal efficiency. The decrease in sorption density can be attributed to the fact that some sorption sites remain unsaturated during the sorption process (Rengaraj et al., 2003).

\subsection{Effect of initial pesticide concentration}

Initial pesticide concentration in aquatic solutions is of great importance when considering pesticide removal by sorption. The results showed that with an increase in initial concentration from 0.01 to $1.8 \mathrm{mmol} / \mathrm{L}$, the removal percentage of bentazone dropped from $99.0 \%$ to

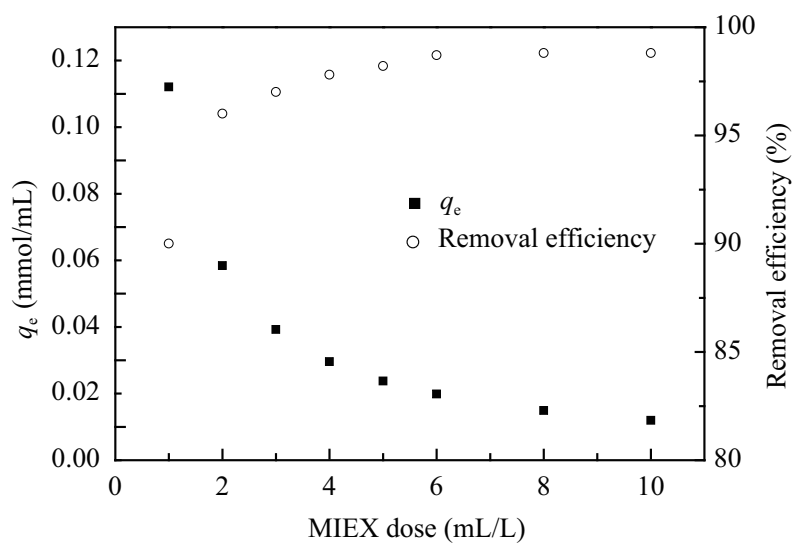

Fig. 1 Effect of resin amount on the adsorption of bentazone at initial bentazone concentration $0.08 \mathrm{mmol} / \mathrm{L}$ and temperature $(25 \pm 1)^{\circ} \mathrm{C} . q_{\mathrm{e}}$ : sorption density of bentazone on MIEX resion at equlibrium.

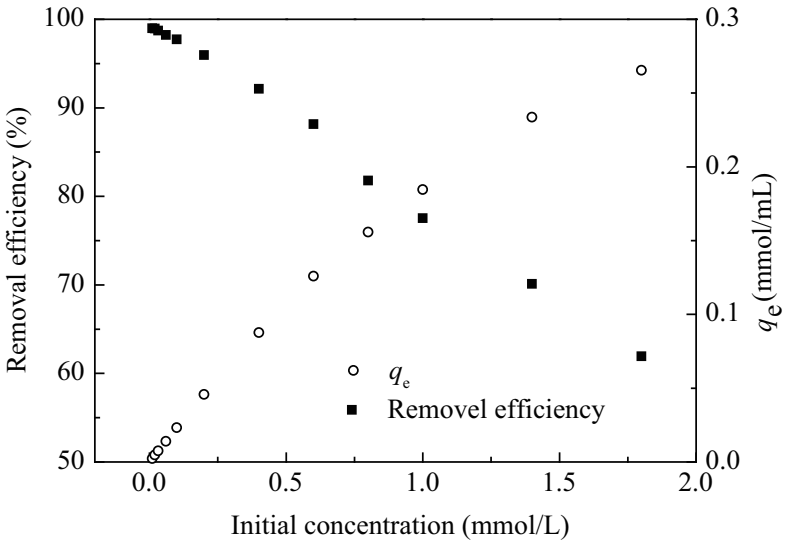

Fig. 2 Effect of initial concentration on the sorption of bentazone.

$61.9 \%$ and adsorption density increased from 0.002 to 0.26 $\mathrm{mmol} / \mathrm{mL}$ for a resin dose of $4.2 \mathrm{~mL} / \mathrm{L}$ (Fig. 2). The resins have a limited number of exchange sites, which become saturated above a certain bentazone concentration. The increase in adsorption density may be due to the utilization of all active sites available for sorption at higher pesticide concentration (Gupta and Babu, 2009).

\subsection{Kinetic study}

Figure 3 shows the effect of reaction time on the removal of bentazone by MIEX resin. Curves of different initial concentrations showed a similar trend. Initially, MIEX-bound bentazone concentration increased rapidly to approximately $30 \mathrm{~min}$, and then plateaued gradually to 60 min. A further increase in contact time had a negligible effect on bentazone sorption. Sorption rate was initially higher due to the great availability of resin exchange sites. Maximum removal efficiencies were $98.7 \%, 97.9 \%$ and $96.7 \%$ for bentazone at the initial concentrations of 0.04 , $0.08,0.12 \mathrm{mmol} / \mathrm{L}$, respectively. The results revealed that MIEX resin sorption was fast and effective in bentazone removal. Previous research on the application of MIEX resin for NOM control has shown that most dissolved organic matter (DOM) and $\mathrm{UV}_{254}$ removal occurs in the first 15-30 min (Singer and Bilyk, 2002; Fearing et al., 2004; Boyer and Singer, 2005). It has also been suggested

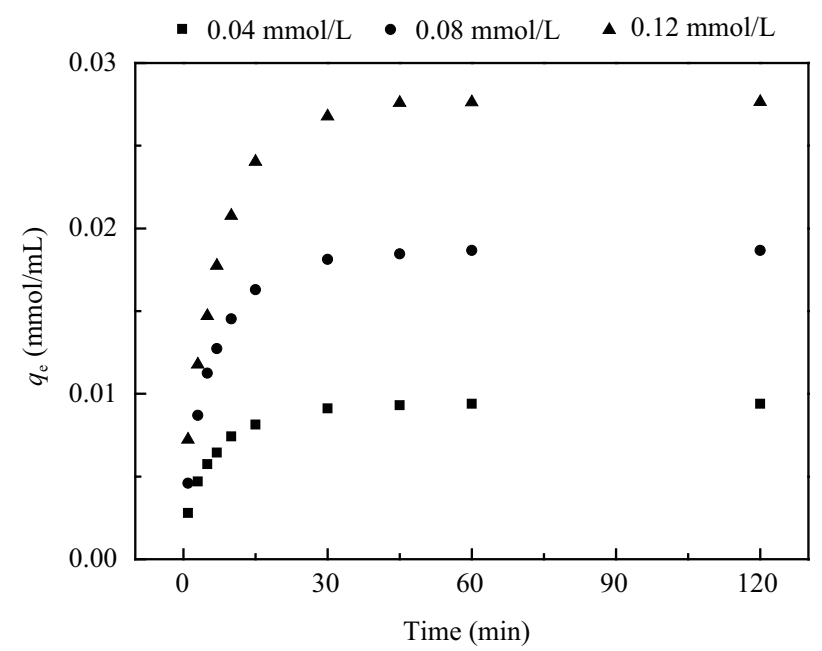

Fig. 3 Effect of reaction time on the sorption of bentazone on MIEX preloaded with $4.2 \mathrm{~mL} / \mathrm{L}$ at $(25 \pm 1)^{\circ} \mathrm{C}$. 
that $30 \mathrm{~min}$ is a typical detention time for using MIEX resin (Slunjski et al., 2000). Ion exchange with chloride is the dominant mechanism for NOM removal at the beginning $30 \mathrm{~min}$, thereby the resin can be regenerated more easily (Slunjski et al., 2000).

To further understand the sorption kinetic process of bentazone using MIEX resin, experimental data from Fig. 3 were analyzed using pseudo first-order and second-order kinetic models. These two models can be expressed as following Eqs. (1) and (2) (Rengaraj et al., 2003; Ho and McKay, 1999a) and the rate constants are shown in Tables 2 and 3.

Pseudo first-order:

$$
\ln \left(1-U_{t}\right)=-k t ; \quad U_{t}=\frac{a-C_{t}}{a-C_{\mathrm{e}}}
$$

Pseudo second-order:

$$
\frac{t}{q_{t}}=\frac{1}{k_{\mathrm{ad}} q_{\mathrm{e}}^{2}}+\frac{t}{q_{\mathrm{e}}} ; \quad h=k_{\mathrm{ad}} q_{\mathrm{e}}^{2}
$$

where, $a(\mathrm{mmol} / \mathrm{L})$ is the initial pesticide concentration, $C_{t}$ $(\mathrm{mmol} / \mathrm{L})$ and $C_{\mathrm{e}}(\mathrm{mmol} / \mathrm{L})$ are the pesticide concentration at time $t$ and equilibrium, respectively, $U_{t}$ is the ratio of pesticide concentration at time $t$ and equilibrium in the solid phase, $k\left(\mathrm{~min}^{-1}\right)$ is the sorption rate constant of first-order equation, $q_{t}(\mathrm{mmol} / \mathrm{mL})$ and $q_{\mathrm{e}}(\mathrm{mmol} / \mathrm{mL})$ are the pesticide concentration at time $t$ and equilibrium in the solid phase, respectively, $k_{\mathrm{ad}}(\mathrm{mL} /(\mathrm{mmol} \cdot \mathrm{min}))$ is the sorption rate constant of pseudo second-order equation, and $h(\mathrm{mmol} /(\mathrm{mL} \cdot \mathrm{min}))$ represents the initial sorption rate.

The pseudo second-order model assumes the sorption rate is controlled by chemical sorption and the sorption capacity is proportional to the number of active sites on the sorbent (Ho and McKay, 1999a). This model has successfully described many adsorption processes over the whole time range (Alhamed, 2009; Gupta and Babu, 2009). As shown in Table 3, the calculated $q_{\mathrm{e}}$ values, such as $0.0097,0.0193$ and 0.0287 , are well in agreement with the experimental values $0.0094,0.0187,0.0276 \mathrm{mmol} / \mathrm{mL}$ at the three given initial bentazone concentrations, respectively. The relatively high correlation coefficients $\left(R^{2}>\right.$ 0.999) showed that the pseudo second-order model could

Table 2 Pseudo first-order equation rate constant values for bentazone adsorption on MIEX resin

\begin{tabular}{lllll}
\hline $\begin{array}{l}\text { Bentazone } \\
(\mathrm{mmol} / \mathrm{L})\end{array}$ & $\begin{array}{l}k \\
\left(\mathrm{~min}^{-1}\right)\end{array}$ & $\begin{array}{l}k_{1} \\
\left(\mathrm{~min}^{-1}\right)\end{array}$ & $\begin{array}{l}k_{2} \\
\left(\mathrm{~min}^{-1}\right)\end{array}$ & $R^{2}$ \\
\hline 0.04 & 0.1426 & 0.1408 & 0.0018 & 0.9100 \\
0.08 & 0.1418 & 0.1390 & 0.0028 & 0.9085 \\
0.12 & 0.1210 & 0.1171 & 0.0039 & 0.9968 \\
\hline
\end{tabular}

$k$ : overall rate constant; $k_{1}$ : forward rate constant; $k_{2}$; backward rate constant. be better applied for the entire sorption process than the first-order model.

Kinetics was controlled by various mechanisms and steps in ion-exchange phenomena. Four major ratelimiting steps are generally cited (Ho and McKay, 1999b; Krishna et al., 2000): (1) mass transfer of solute from solution to the boundary film; (2) mass transfer of solute from boundary film to surface; (3) sorption and ion exchange of ions onto sites; and (4) internal diffusion of solute. The third step is assumed to be very rapid and non-limiting in this kinetic analysis; sorption is a rapid phenomenon. The first and the second steps are external mass transfer resistance steps, depending on various parameters such as agitation and homogeneity of solution. The fourth one is an internal particle diffusion resistance step. The most commonly used technique for identifying the mechanism involved in the adsorption process was fitting the intraparticle diffusion plot.

The equation is given by Weber and Morris (1962):

$q=k_{\mathrm{id}} t^{1 / 2}$

where, $q(\mathrm{mmol} / \mathrm{mL})$ is the amount adsorbed at time $t$ (min), and $k_{\mathrm{id}}\left((\mathrm{mmol} / \mathrm{mL}) / \mathrm{min}^{1 / 2}\right)$ is the intraparticle diffusion rate constant. The intraparticle model assumes that the external diffusion is negligible, and intraparticle diffusion is the only rate-controlling step, which is usually true for the well-mixed solution. The initial kinetic data from 1 to $15 \mathrm{~min}$ were used to plot the relationship of $q$ versus $t^{1 / 2}$ for different initial bentazone concentrations as shown in Fig. 4 and constants calculated as shown in Table 3. The linear correlation relationships between $q$ and $t^{1 / 2}$ implied that intraparticle diffusion processes limited the sorption of bentazone onto MIEX resin.

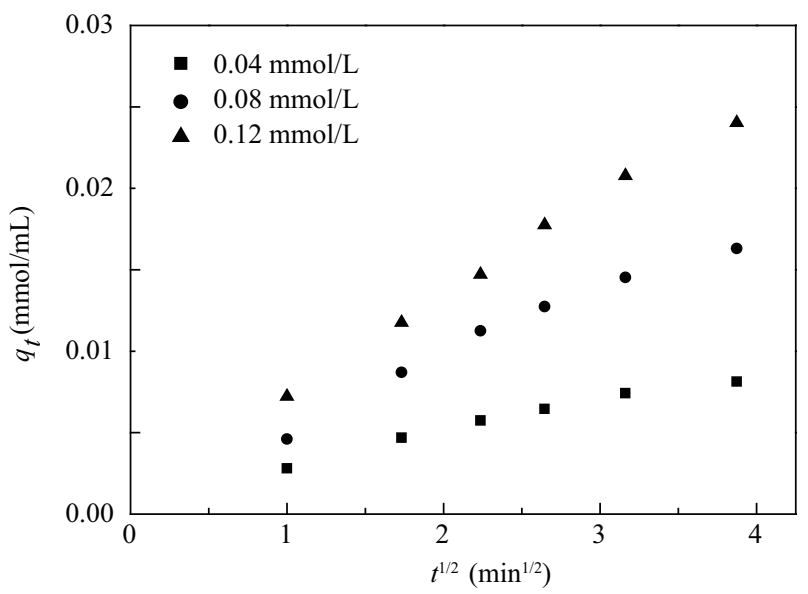

Fig. 4 Intraparticle diffusion plots for the sorption of bentazone on MIEX resin.

Table 3 Pseudo second-order rate constant values for bentazone adsorption on MIEX resin

\begin{tabular}{llllrr}
\hline $\begin{array}{l}\text { Bentazone } \\
(\mathrm{mmol} / \mathrm{L})\end{array}$ & $\begin{array}{l}k_{\mathrm{ad}} \\
(\mathrm{mL} /(\mathrm{mmol} \cdot \mathrm{min}))\end{array}$ & $\begin{array}{l}q_{\mathrm{e}} \\
(\mathrm{mmol} / \mathrm{mL})\end{array}$ & $\begin{array}{l}h \\
(\mathrm{mmol} /(\mathrm{mL} \cdot \mathrm{min}))\end{array}$ & $R^{2}$ & $\begin{array}{l}k_{\text {id }} \\
\left((\mathrm{mmol} / \mathrm{mL}) / \mathrm{min}{ }^{1 / 2}\right)\end{array}$ \\
\hline 0.04 & 38.5121 & 0.0097 & 0.0036 & 0.9996 & 0.0023 \\
0.08 & 17.1767 & 0.0193 & 0.0064 & 0.9996 & 0.0046 \\
0.12 & 9.816 & 0.0287 & 0.0081 & 0.9994 & 0.0065 \\
\hline
\end{tabular}




\subsection{Isotherm study}

Sorption isotherms are expressed in terms of the relationship between adsorbate concentration in the liquid and the amount of adsorbate adsorbed by the unit volume of adsorbent at a constant temperature. To further understand sorbate-sorbent interactions, the removal characteristics of another ionic herbicide (glyphosate) by MIEX resin were studied. Our pre-experiment results showed that the sorption kinetic process of glyphosate using MIEX resin was similar to bentazone, therefore the kinetic data of glyphosate are not shown. Sorption isotherm models Freundlich and Langmuir equations (Genc-Fuhrman et al., 2004), were used to describe the experimental data:

Freundlich equation:

$$
q_{\mathrm{e}}=K C_{\mathrm{e}}^{\frac{1}{n}}
$$

Langmuir equation:

$$
q_{\mathrm{e}}=\frac{b q_{\mathrm{m}} C_{\mathrm{e}}}{1+b C_{\mathrm{e}}}
$$

where, $q_{\mathrm{e}}(\mathrm{mmol} / \mathrm{mL})$ is the equilibrium pesticide concentration in the adsorbent, $C_{\mathrm{e}}(\mathrm{mmol} / \mathrm{L})$ is the equilibrium pesticide concentration in solution, $K$ $\left((\mathrm{mg} / \mathrm{mL}) /(\mathrm{mg} / \mathrm{L})^{1 / n}\right)$ and $n$ are the constants of Freundlich equation, and $q_{\mathrm{m}}(\mathrm{mmol} / \mathrm{mL})$ and $b(\mathrm{~L} / \mathrm{mg})$ are the maximum sorption capacity and the sorption constant of

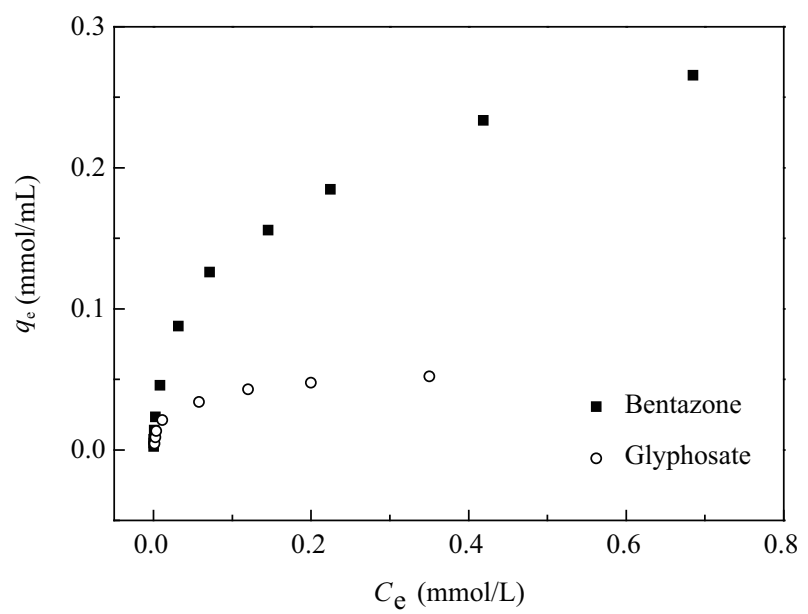

Fig. 5 Sorption isotherms of bentazone and glyphosate on MIEX preloaded with $4.2 \mathrm{~mL} / \mathrm{L}$ at $(25 \pm 1)^{\circ} \mathrm{C}$.
Langmuir equation, respectively.

As shown in Fig. 5 and Table 4, high correlation coefficients revealed that both the Freundlich and Langmuir model could well describe the sorption isotherms of bentazone and glyphosate. The maximum sorption capacity calculated from the Langmuir equation was $0.2656 \mathrm{mmol} / \mathrm{mL}$ for bentzone and $0.0511 \mathrm{mmol} / \mathrm{mL}$ for glyphosate. It is apparent that the removal capacity of MIEX resin for bentazone was much higher than that for glyphosate.

The mechanism of organic substance uptake by anion exchange resins, such as adsorption versus ion exchange, has not been conclusively demonstrated. The resin structure, the characteristic of target sorbate, and the sorption environment all affect the interactions of sorbate and sorbent. Fu and Symons (1990) concluded that DOC was removed via ion exchange, while Carmona et al. (2006) observed that both adsorption and ion exchange occurred on the removal of phenol using IRA-420 resin. Boyer and Singer (2008) compared the DOC removal results of MIEX resin with a weak-acid magnetic ion exchange (WAMIEX), which was similar in composition to the MIEX resin but had no anion exchange properties, and confirmed that the removal of DOC by MIEX resin occurred exclusively via ion exchange.

Bentazone is a herbicide with $\mathrm{p} K_{\mathrm{a}}$ of 3.3 , thus it exists predominantly in anionic form under natural aquatic environments. The molecular structure and dissociation equilibrium of bentazone is shown in Fig. 6 (Ania and Béguin, 2007).

Based on previous work, we developed an initial hypothesis that bentazone was removed by ion exchange. Three sorption systems of bentazone $/ \mathrm{Cl}^{-}$, bentazone $/ \mathrm{SO}_{4}{ }^{2-} / \mathrm{Cl}^{-}$, and bentazone $/ \mathrm{NO}_{3}{ }^{-} / \mathrm{Cl}^{-}$were studied. The charge balance equations for the ion exchange between $\mathrm{Cl}^{-}$and bentazone, $\mathrm{SO}_{4}{ }^{2-}$ and $\mathrm{NO}_{3}{ }^{-}$are written as follows:

$$
\begin{aligned}
& \overline{\mathrm{Cl}^{-}}+\mathrm{Cl}^{-}+\text {bentazone }= \\
& \quad \overline{\mathrm{Cl}^{-}}+\overline{\text { bentazone }}+\mathrm{Cl}^{-}+\text {bentazone } \\
& \overline{\mathrm{Cl}^{-}}+\mathrm{Cl}^{-}+\mathrm{NO}_{3}^{-}=\overline{\mathrm{Cl}^{-}}+\overline{\mathrm{NO}_{3}^{-}}+\mathrm{Cl}^{-}+\mathrm{NO}_{3}^{-} \\
& \overline{\mathrm{Cl}^{-}}+\mathrm{Cl}^{-}+2 \mathrm{SO}_{4}^{2-}=\overline{\mathrm{Cl}^{-}}+2 \overline{\mathrm{SO}_{4}^{2-}}+\mathrm{Cl}^{-}+2 \mathrm{SO}_{4}^{2-}
\end{aligned}
$$

\begin{tabular}{|c|c|c|c|c|c|c|}
\hline & \multicolumn{3}{|c|}{ Freundlich isotherm } & \multicolumn{3}{|c|}{ Langmuir isotherm } \\
\hline & $\begin{array}{l}K \\
\left((\mathrm{mg} / \mathrm{mL}) /(\mathrm{mg} / \mathrm{L})^{1 / n}\right)\end{array}$ & $n$ & $R^{2}$ & $\begin{array}{l}q_{\mathrm{m}} \\
(\mathrm{mmol} / \mathrm{mL})\end{array}$ & $\begin{array}{l}b \\
(\mathrm{~L} / \mathrm{mg})\end{array}$ & $R^{2}$ \\
\hline Bentazone & 0.4348 & 1.9008 & 0.9781 & 0.2656 & 22.899 & 0.9735 \\
\hline Glyphosate & 0.0969 & 2.5189 & 0.9412 & 0.0551 & 48.6718 & 0.9916 \\
\hline
\end{tabular}

where, overbars represent the concentration in the resin-

Table 4 Freundlich and Langmuir isotherm constants for bentazone and glyphosate<smiles>CC(C)N1C(=O)c2ccccc2NS1(=O)=O</smiles>

Fig. 6 Molecular structure of bentazone, keto-enol tautomerism and dissociation equilibrium. 


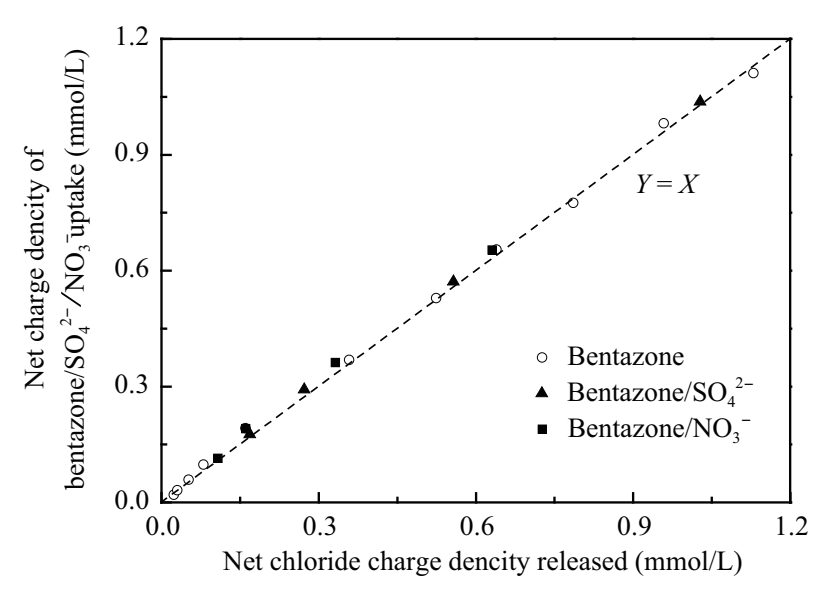

Fig. 7 Illustrative ion exchange stoichiometry for MIEX resin.

phase $(\mathrm{mmol} / \mathrm{mL})$ and the others represent concentrations in solution $(\mathrm{mmol} / \mathrm{L})$. For ion exchange reaction, at equilibrium the decrease in the aqueous-phase charge density of bentazone, $\mathrm{SO}_{4}{ }^{2-}$ and $\mathrm{NO}_{3}{ }^{-}$must equal the increase in the aqueous-phase charge density of chloride. The plots are shown in Fig. 7. The $X$-axis shows the net increase charge density of chloride, and the $Y$-axis shows the net decrease charge density of bentazone, $\mathrm{SO}_{4}{ }^{2-}$ and $\mathrm{NO}_{3}{ }^{-}$ for each system. All data points for the three sorption systems are clustered tightly about the $Y=X$ line and the maximum relative difference between chloride released and the sorbates taken up was calculated as less than $21 \%$. These results verified that bentazone was predominantly removed by ion exchange.

To further examine the relative contributions of ion exchange and adsorption to bentazone removal, we studied the removal efficiency of MIEX resin for parathion-methyl pesticide, which had non ionic moiety. As expected, the non-ionic pesticide was poorly removed by MIEX resin. With an initial concentration of 0.1 to $0.8 \mathrm{mg} / \mathrm{L}$, a resin dose of $8 \mathrm{~mL} / \mathrm{L}$ and contact time of $30 \mathrm{~min}$, the sorption percentage of parathion-methyl was less than $10 \%$ (results not shown). Poor non-ionic pesticides removal efficiency has also been observed by Humbert et al. (2005), who studied the performance of MIEX resin for atrazine and isoproturon treatment. These results confirm that bentazone was removed by ion exchange.

The composition of most ion exchange resins is either polystyrene or polyacrylic, with polyacrylic resins being more hydrophilic than polystyrene resins. MIEX resin is a polyacrylic resin and clusters of polar water molecules are assembled on the resin surface. Once the sorbate bentazone or parathion-methyl enters the exchanger phase, the water clusters hamper the hydrophobic interactions between the nonpolar moiety of sorbate and the nonpolar matrix of the ion exchanger, thereby adsorption on MIEX resin is neglectable.

Bentazone and glyphosate are both ionic herbicides, but the sorption capacity of bentazone on MIEX resin was obviously higher than glyphosate (Fig. 5). This result is related to the molecular structure of the two organic materials. In water, the ionic charge of bentazone and glyphosate react with water molecules through ion-dipole interaction, and therefore these two compounds have rela- tively high water solubility. Unlike glyphosate, however, bentazone has both ionic charge and nonpolar moiety and is a hydrophobic ionizable organic compound. In a solution system, the sorption of sorbates occurs not only because the sorbates are attracted by the sorbent but also because the solution might be 'rejecting' them. Similar interactions occur during desolvation of pentachlorophenol $\left(\mathrm{PCP}^{-}\right)$in water (Li and Sengupta, 1998). When bentazone was introduced into water (a polar solvent) in the present study, the water molecules may have turned from the aromaticity (hydrophobicity) of bentazone and reorganized themselves in clusters through hydrogen bonding. This hydrophobic effect increased the solution phase fugacity of bentazone, and provided an entropic driving force for bentazone removal from solution. The removal process of glyphosate by MIEX resin lacks this entropy assisted effect, thus the sorption capacity of glyphosate was much lower than bentazone.

\section{Conclusions}

Using MIEX resin as the sorbent to remove bentazone contamination was an effective method in water supply treatment. The experimental results indicated that $30 \mathrm{~min}$ was a typical and suitable detention time. Kinetics of bentazone removals using MIEX resin fitted well with the pseudo second-order model and intraparticle diffusion was considered the dominant rate controlling step. MIEX resin prossessed the highest sorption capacity of $0.2656 \mathrm{mmol} / \mathrm{mL}$ for bentazone according to Langmuir fitting. Both ionic charges and nonpolar moiety of bentzone governed its sorption characteristics. Compared with removal results of glyphosate and non-ionic pesticides, we concluded that MIEX resin preferentially removed hydrophobic ionizable organic compounds. Ion exchange was the dominant mechanism for bentazone removal by MIEX resin.

\section{Acknowledgments}

This work was supported by the National High-Tech Research and Development Program (863) of China (No. 2008AA06A414) and the National Natural Science Foundation of China (No. 50921064). We thank Orica Watercare for supplying MIEX resins.

\section{References}

Ayranci E, Hoda N, 2004. Studies on removal of metribuzin, bromacil, 2,4-D and atrazine from water by adsorption on high area carbon cloth. Journal of Hazardous Materials, 112: $163-168$.

Ania C O, Béguin F, 2007. Mechanism of adsorption and electrosorption of bentazone on activated carbon cloth in aqueous solutions. Water Research, 41: 3372-3380.

Abdessalem A K, Bellakhal N, Oturan N, Dachraoui M, Oturan M A, 2010. Treatment of a mixture of three pesticides by photo- and electro-Fenton processes. Desalination, 250: 450-455.

Anderson C T, Maier W J, 1979. Trace organics removal by anion 
exchange resins. Journal of the American Water Works Assocication, 71(5): 278-283.

Alhamed Y A, 2009. Adsorption kinetics and performance of packed bed adsorber for phenol removal using activated carbon from dates' stones. Journal of Hazardous Materials, 170: 763-770.

Boening P H, Beckmann D D, Snoeyink V L, 1980. Activated carbon versus resin adsorption of humic substances. Journal of the American Water Works Assocication, 72: 54-59.

Bolto B, Dixon D, Eldridge R, King S, 2002. Removal of THM precursors by coagulation or ion exchange. Water Research, 36: 5066-5073.

Boyer T H, Singer P C, 2005. Bench-scale testing of a magnetic ion exchange resin for removal of disinfection by-product precursors. Water Research, 39: 1265-1276.

Boyer T H, Singer P C, 2008. Stoichiometry of removal of natural organic matter by ion exchange. Envionmental Science and Technology, 42(2): 608-613.

Cohen Z Z, Eiden C C, Lober M N, 1986. Evolution of pesticide in ground water. In: ACS Symposium Series (Ser. 315) (Gerner W Y, ed.). American Chemical Society, Washington DC. 170-196.

Carrizosa M J, Calderón M J, Hermosín M C, Cornejo J, 2000. Organosmectites as sorbent and carrier of the herbicide bentazone. Science of the Total Environment, 247: 285-293.

Caus A, Vanderhaegen S, Braeken L, Van der Bruggen B, 2009. Integrated nanofiltration cascades with low salt rejection for complete removal of pesticides in drinking water production. Desalination, 241: 111-117.

Carmona M, De Lucas A, Valverde J L, Velasco B, Rodríguez J F, 2006. Combined adsorption and ion exchange equilibrium of phenol on Amberlite IRA-420. Chemical Engineering Journal, 117: 155-160.

Fearing D A, Banks J, Guyetand S, Monfort E C, Jefferson B, Wilson D et al., 2004. Combination of ferric and MIEX for the treatment of humic rich waters. Water Research, 38: 2551-2558.

Fu P L K, Symons J M, 1990. Removing aquatic organic substances by anion exchange resins. Journal of the American Water Works Assocication, 82(10): 70-77.

Gerstl Z, 1991. Behavior of organic agrochemicals in irrigated solids. In: Chemistry, Agriculture and the Environment, (Richardson M L, eds.). The Royal Society of Chemistry, Cambridge, UK. 332.

Genc-Fuhrman H, Tjell J C, McConchie D, 2004. Adsorption of arsenic from water using activated neutralized red mud. Environmental Science and Technology, 38: 2428-2434.

Gupta S, Babu B V, 2009. Removal of toxic metal Cr(VI) from aqueous solutions using sawdust as adsorbent: Equilibrium, kinetics and regeneration studies. Chemical Engineering Journal, 150: 352-365.
Huber R, Otto S, 1994. Environmental behavior of bentazone herbicide. Reviews of Environmental Contamination and Toxicology, 137: 111-134.

Humbert H, Gallard H, Suty H, Croué J P, 2005. Performance of selected anion exchange resins for the treatment of a high DOC content surface water. Water Research, 39: 16991708.

Ho Y S, Mckay G, 1999a. Pseudo-second order model for sorption processes. Process Biochemisty, 34: 451.

Ho Y S, McKay G, 1999b. Competitive sorption of copper and nick ions from aqueous solution using peat. Adsorption, 5: 409-417.

Kobayashi K, Rompas R M, Maekawa T, Imada N, Oshima Y, 1990. Studies on the relation between toxicity and metabolism of organophosphorus insecticides in shrimps. 5. Changes in metabolic-activity of tiger shrimp larvae at different stages to fenitrothion, an organophosphorus insecticide. Nippon Suisan Gakkaishi, 56(3): 489-496.

Krishna B S, Murty D S R, Jai Prakash B S, 2000. Thermodynamics of Chromium(VI) anionic species sorption onto surfactant-modified montmorillonite clay. Journal of Colloid and Interface Science, 229(1): 230-236.

Li P, Sengupta A K, 1998. Genesis of selectivity and reversibility for sorption of synthetic aromatic anions onto polymeric sorbents. Environmental Science and Technology, 32: 3756-3766.

Pelekani C, Snoeyink V L, 2000. Competitive adsorption between atrazine and methylene blue on activated carbon: the importance of pore size distribution. Carbon, 38(10): 1423 1436.

Rengaraj S, Joo C K, Kim Y, Yi J, 2003. Kinetics of removal of chromium from water and electronic process wastewater by ion exchange resins: $1200 \mathrm{H}, 1500 \mathrm{H}$ and IRN97H. Journal of Hazardous Materials, 102: 257-275.

Streat M, Horner D J, 2000. Adsorption of highly soluble herbicides from water using activated carbon and hypercrosslinked polymers. Transactions of the Institute of Chemical Engineers, Part B, 78: 363-382.

Slunjski M, Bourke M, O’Leary B, 2000. MIEX DOC Process for removal of humics in water treatment. In: International Humic Substances Society Australian Chapter Meeting Melboume, Australia.

Singer P C, Bilyk K, 2002. Enhanced coagulation using a magnetic ion exchange resin. Water Research, 36: 40094022.

Taylor J C, Hong S K, 2000. Potable water quality and membrane technology. Laboratory Medicine, 31: 563-568.

Weber W J, Morris C J, 1962. Advances in water pollution research. In: Proceedings of the First International Conference on Water Pollution Research (Volume 2). Pergamon Press, Oxford. 231 